\title{
A prospective study of demographic features and quality of life in HIV-positive women with cervical cancer treated at Tygerberg Hospital
}

\begin{tabular}{|c|c|}
\hline \multicolumn{2}{|c|}{$\begin{array}{l}\text { Authors: } \\
\text { George du Toit }{ }^{1} \\
\text { Martin Kidd }{ }^{2}\end{array}$} \\
\hline \multicolumn{2}{|c|}{$\begin{array}{l}\text { Affiliations: } \\
{ }^{1} \text { Department of Obsterics } \\
\text { and Gynaecology, } \\
\text { Stellenbosch University, } \\
\text { South Africa }\end{array}$} \\
\hline $\begin{array}{l}{ }^{2} \text { Centre for St } \\
\text { Consultation, } \\
\text { University, Sc }\end{array}$ & $\begin{array}{l}\text { Stistical } \\
\text { Stellenbosch } \\
\text { uth Africa }\end{array}$ \\
\hline \multicolumn{2}{|c|}{$\begin{array}{l}\text { Correspondence to: } \\
\text { George du Toit }\end{array}$} \\
\hline \multicolumn{2}{|c|}{$\begin{array}{l}\text { Email: } \\
\text { dutoitg@worldonline.co.za }\end{array}$} \\
\hline \multicolumn{2}{|c|}{$\begin{array}{l}\text { Postal address: } \\
\text { Private Bag X1, Matieland } \\
7602 \text {, South Africa }\end{array}$} \\
\hline \multicolumn{2}{|c|}{$\begin{array}{l}\text { Received: } 05 \text { Mar. } 2015 \\
\text { Accepted: } 06 \text { Aug. } 2015 \\
\text { Published: } 18 \text { Sept. } 2015\end{array}$} \\
\hline \multicolumn{2}{|c|}{$\begin{array}{l}\text { How to cite this article: } \\
\text { Du Toit G, Kidd M. A } \\
\text { prospective study of } \\
\text { demographic features } \\
\text { and quality of life in } \\
\text { HIV-positive women with } \\
\text { cervical cancer treated at } \\
\text { Tygerberg Hospital. S Afr J } \\
\text { HIV Med. 2015;16(1), Art. } \\
\text { \#368, } 5 \text { pages. http://dx.doi. } \\
\text { org/10.4102/sajhivmed. } \\
\text { v16i1.368 }\end{array}$} \\
\hline \multicolumn{2}{|c|}{$\begin{array}{l}\text { Copyright: } \\
\text { (C) 2015. The Authors. } \\
\text { Licensee: AOSIS } \\
\text { OpenJournals. This work is } \\
\text { licensed under the Creative } \\
\text { Commons Attribution } \\
\text { License. }\end{array}$} \\
\hline \multicolumn{2}{|l|}{ Read online: } \\
\hline 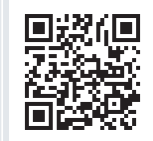 & $\begin{array}{l}\text { Scan this QR } \\
\text { code with your } \\
\text { smart phone or } \\
\text { mobile device } \\
\text { to read online. }\end{array}$ \\
\hline
\end{tabular}

Authors:

George du Toit

and Gynaecology,

Stellenbosch University,

${ }^{2}$ Centre for Statistical

Consultation, Stellenbosch

Correspondence to:

George du Toit

Email:

Postal address:

Private Bag X1, Matieland

Accepted: 06 Aug 2015

Published: 18 Sept. 2015

How to cite this article:

and quality of

HIV-positive women with

cervical cancer treated at

Tygerberg Hospital. S Afr J

HIV Med. 2015;16(1), Art.

\#368, 5 pages. http://dx.

v16i1.368

Copyright:

Licensee: AOSIS

OpenJournals. This work is licensed under the Creative

Commons Attribution

License.

mobile device
to read online.
Background: Cervical cancer and human immunodeficiency virus (HIV) infection/acquired immune deficiency syndrome (AIDS) both have a high incidence in South Africa. Cervical cancer treatment of HIV-positive women poses challenges. Treatment-related changes in quality of life (QOL) of such women are important to future treatment protocols.

Aim: To examine demographic data of HIV-negative and HIV-positive women at diagnosis of cervical cancer and describe their changes in QOL as a result of treatment.

Methods and materials: All newly diagnosed patients with cervical cancer at Tygerberg Hospital were approached to participate in the study. The European Organisation for Research and Treatment of Cancer Quality of Life Core Questionnaire (EORTC QLQ-C30) and the Cervix Cancer Module (QLQ-CX24) were used. General QOL was measured with the EORTC QLQ-C30 and cervical-specific QOL with the QLQ-CX24 questionnaire. The patients completed the questionnaire at diagnosis, on completion of treatment and at 3 months' follow-up.

Results: The study included a total of 221 women of whom $22 \%$ were HIV-positive; the latter were younger and of higher educational level than the rest. Mean monthly income and stage distribution was similar between the two groups. HIV-positive patients underwent radiation therapy more commonly than chemoradiation. HIV-positive women showed statistically significantly higher loss to follow-up during the study. HIV-positive women experienced no improvement in insomnia, appetite loss, nausea, vomiting, diarrhoea, social role or any of the sexual domains. In contrast, HIV-negative women experienced statistically significant improvement in all sexual domains other than sexual/vaginal functioning. The QOL improvement of HIV-negative women was statistically significantly greater than their HIV-positive counterparts in the majority of QOL domains. Global health improved in both groups, with HIV-negative women experiencing greater improvement. HIV-positive women experienced an initial decline of peripheral neuropathy (PN) symptoms post treatment with a return to pretreatment values at 3 months' follow-up. The change in PN was statistically significant between the HIV-negative and HIV-positive women.

Conclusion: Demographic differences exist between the HIV-negative and HIV-positive groups. The differential outcome in the QOL of HIV-positive and HIV-negative women treated for cervical cancer might be related to persistence of AIDS-related symptoms on completion of cervical cancer treatment.

\section{Introduction}

The quality of life (QOL) of human immunodeficiency virus (HIV)-positive women with cervical cancer is the result of both diseases and the impact of their respective treatments. Invasive cervical cancer is an acquired immune deficiency syndrome (AIDS)-defining condition (World Health Organization stage 4). ${ }^{1}$ AIDS is endemic in sub-Saharan Africa. The South African population has a $12 \%-18 \%$ incidence of HIV-positivity. ${ }^{2}$ South Africa has a cervical cancer incidence rate of 26.8/100 000. ${ }^{3}$ Most South African women present at an advanced stage of the disease. Cervical cancer and HIV infection are epidemiologically related owing to the sexual transmission of both conditions. Peripheral neuropathy (PN) in HIV-infected persons occurs in $50 \%-60 \%$ of cases. At autopsy, PN can be shown in all HIV-positive persons despite their having no signs or symptoms during their lifetime. Antiretroviral medication (particularly didanosine, zalcitabine and stavudine) is directly neurotoxic and results in PN identical to AIDS-associated neuropathy. The disease and its treatment synergistically increase PN. Cisplatin is the drug of choice in chemoradiation (CR) treatment of cervical cancer. Cisplatin results, in a dose-dependent fashion, in sensory $\mathrm{PN}$ in the stocking-glove distribution. ${ }^{4}$ Poor tolerance of chemotherapy for cervical 
cancer by HIV-positive women results in substantially less completion of CR than their HIV-negative counterparts. The use of CR in advanced stage (III to IVA) cervical cancer in HIV-positive women has been questioned owing to the limited survival benefit. ${ }^{5}$ A Cochrane review shows a statistically non-significant 3\% benefit in 5-year survival of CR over radiation therapy (RT) in stage III to IVA. ${ }^{6}$ Simonds et al. ${ }^{5}$ suggest that the omission of chemotherapy in these HIV-positive women with cervical cancer would result in timely completion of the full dose of radiation therapy.

A limitation of the study by Simonds et al. ${ }^{5}$ was the $15.4 \%$ (59 out of a cohort of 383) incidence of HIV-positive women. ${ }^{5}$ Data on the impact of RT on QOL of HIV-positive women with cervical cancer are lacking. The aim of the present study was to examine demographic data for HIV-negative and HIV-positive women at diagnosis of cervical cancer and to describe QOL changes in these women after treatment for cervical cancer.

\section{Methods and materials Inclusion criteria}

Patients referred to the Unit of Gynaecologic Oncology at Tygerberg Hospital who had newly diagnosed cervical cancer were approached to participate in the study. The unit is one of two tertiary referral units for public-sector patients in Western Cape Province. The province has a population of 5.8 million. Most (85\%) of the population do not have private medical insurance and are dependent on public facilities provided by two tertiary hospitals (Tygerberg Hospital and Groote Schuur Hospital) for treatment of cervical cancer. ${ }^{7}$ Patients were eligible for the study if they had histologically proven cervical cancer. Exclusion criteria included concurrent, or previous history of, cancers and medical disorders that might affect QOL, such as diabetes. Patients unable to provide informed consent owing to psychiatric disorders were excluded. Cervical cancer was staged according to international guidelines.$^{8}$ Clinical management included HIV testing and initiation of antiretroviral treatment. HIVpositive women did not receive chemotherapy if their CD4 count was $<200$ cells $/ \mu \mathrm{L}$, or active tuberculosis was present.

\section{Questionnaires}

Patients completed the questionnaire in the language of their choice (isiXhosa, English or Afrikaans) after informed consent was obtained. ${ }^{9}$ A research assistant helped illiterate patients. To exclude bias, the research assistant had no medical background and was not involved in clinical management of the patients. Questionnaires were completed prior to treatment, after initial treatment, and after a 3-month post-treatment period. The follow-up visits coincided with clinical follow-up of patients. Patients failing to attend visits were contacted telephonically where possible. Patient records were used to extract relevant clinical data. Ethical approval was obtained from the local committee (S12/06/174). Clinical management followed protocols as previously described..$^{5}$ The European Organisation for
Research and Treatment of Cancer (EORTC) Quality of Life Core Questionnaire (EORTC QLQ-C30) and the Cervix Cancer Module (QLQ-CX24) were both used. The EORTC QLQ-C30 consists of 30 items comprising 5 functional scales (physical, role, emotional, social and cognitive), 3 symptom scales (fatigue, nausea/vomiting and pain), an overall QOL scale, and 6 individual items (dyspnoea, insomnia, appetite loss, constipation, diarrhoea, and financial difficulties). The EORTC QLQ-C30 was analysed according to the procedures recommended by the EORTC QOL Group. Higher scores on the QLQ-C30 functioning scales and the overall QOL scale indicate a better QOL. Higher scores on the symptom and individual item scales represent a decrease in QOL. ${ }^{10}$ The EORTC QLQ-CX24 includes 3 multi-item scales (symptom experience, body image, and sexual functioning) and 5 singleitem scales (lymphoedema, lower back pain, menopausal symptoms, tingling and numbness, and sexual enjoyment). Higher scores indicate a decrease in QOL except for items 49 and 54 (where higher scores indicate better QOL). ${ }^{11}$ The questionnaires used were translated and validated for use in South Africa. ${ }^{9}$

\section{Statistical analysis}

Descriptive statistics were used to characterise the study sample in terms of the contextual factors of sociodemographic and medical variables. Data presented as medians were analysed using Kruskal-Wallis tests. Post hoc analyses were done with Fisher's least significant difference (LSD) test. Chi-square tests were used for categorical data. A $p$ value $<0.05$ was considered to be significant. Statistical analysis was performed with the use of STATISTICA version 12 software.

\section{Results}

\section{Demographic characteristics}

The study included a total of 221 women (Table 1). HIVpositivity of the study group was $22 \%$. The mean age of the HIV-positive women was statistically significantly 7 years less than that of the HIV-negative women. Age had a normal distribution without any outliers. HIV-positive women had a higher educational grade. Racial distribution shows a statistically significant difference between black $(40 \%)$, mixed race $(12 \%)$ and white $(0 \%)$ participants' HIV-positivity rates. Mean monthly income as well as the percentage of patients under the poverty line were not statistically significantly different between the HIV-positive and -negative groups. Single women had a statistically significantly higher rate of HIV-positivity than their married, widowed and divorced counterparts. The stage distribution of HIV-negative and HIV-positive cases was not statistically significantly different. HIV-positive patients underwent RT more commonly than $\mathrm{CR}$.

Unemployed women had a statistically significantly higher HIV-positivity rate (26\%) than the employed women (23\%). The loss to follow-up of HIV-positive women $v$. HIV-negative women during the post-treatment (56\% v. 34\%) and 3-month 
TABLE 1: Comparative demographic data of HIV-negative and HIV-positive women (poverty line as defined by the Western Cape Provincial Government).

\begin{tabular}{lccc}
\hline Characteristics & $\begin{array}{c}\text { HIV-negative } \\
\boldsymbol{n}=\mathbf{1 7 3}\end{array}$ & $\begin{array}{c}\text { HIV-positive } \\
\boldsymbol{n}=\mathbf{4 8}\end{array}$ & $\boldsymbol{p}$ value \\
\hline Age (years) & 51.34 & 43.94 & $p<0.01$ \\
Mean education level (grade) & 7 & 8 & $p<0.05$ \\
Race (\%) & - & - & $p<0.05$ \\
Mixed race people & 88 & 12 & - \\
Black people & 60 & 40 & - \\
White people & 100 & 0 & - \\
Income (ZAR) & 1450 & 1576 & NS \\
Below poverty line of R3500 (\%) & 79 & 21 & NS \\
Marital state (\%) & - & - & $p<0.05$ \\
Single & 68 & 32 & - \\
Married & 88 & 12 & - \\
Widow & 86 & 14 & - \\
Divorced & 94 & 6 & - \\
Stage distribution & - & - & NS \\
Treatment (\%) & - & - & $p<0.05$ \\
Radiotherapy & 75 & 25 & - \\
Chemoradiation therapy & 88 & 12 & - \\
Employment (\%) & - & - & $p<0.05$ \\
Employed & 77 & 23 & - \\
Pensioner & 93 & 7 & - \\
Unemployed & 74 & 26 & - \\
\hline Source: Wed & & & - \\
\hline
\end{tabular}

Source: Western Cape Provincial Treasury. Regional development profile City of Cape Town. 2012 [cited 2014 Jul 23]. Available from: http://www.westerncape.gov.za/assets/ departments/treasury/dc0_city_of_cape_town_sep-Ig_profile_02_2013.pdf

NS, not significant.

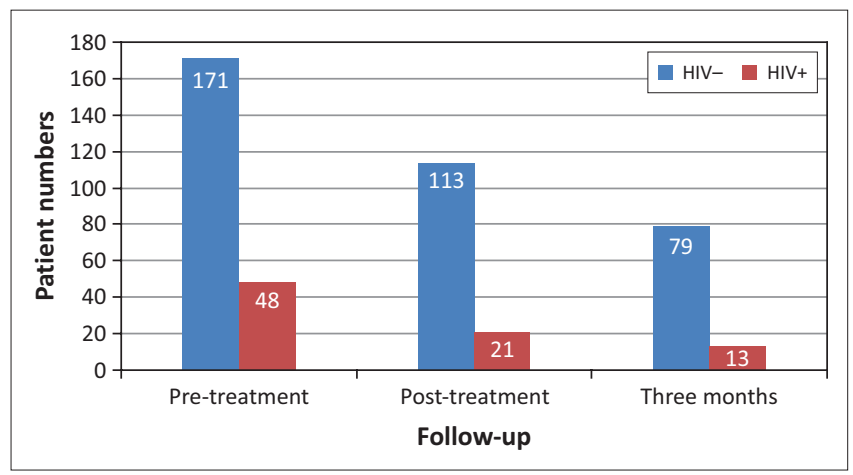

FIGURE 1: Follow-up of HIV-negative versus HIV-positive women over the study period.

(38\% v. 30\%) follow-up visits was statistically significantly higher for the HIV-positive women (Figure 1). Cause and confirmation of death could be accurately determined in 20 women in the total study population.

\section{HIV status and change in quality of life over the study period}

The domains of dyspnoea, financial difficulties, lymphoedema and menopausal symptoms remained unchanged during the study period. HIV-positive women experienced no improvement in insomnia, appetite loss, nausea and vomiting, diarrhoea, social role or any of the sexual domains over the study period. In contrast, HIVnegative women experienced statistically significant improvement in all sexual domains other than sexual/ vaginal function. The improvement in QOL of HIV-negative women was statistically significantly more than their HIVpositive counterparts in all domains, with the exception of
TABLE 2: Change in quality of life during study period.

\begin{tabular}{|c|c|c|c|}
\hline Quality of life domain & HIV- $n=173$ & $\mathrm{HIV}+n=48$ & HIV- versus HIV+ \\
\hline Physical function & $p<0.01 \dagger$ & $p<0.05 \dagger$ & $p<0.05$ \\
\hline Role function & $p<0.01 \%$ & $p<0.01 \%$ & NS \\
\hline Dyspnoea & NS & NS & NS \\
\hline Pain & $p<0.01 \%$ & $p<0.01 \ddagger$ & $p<0.01$ \\
\hline Fatigue & $p<0.01 \ddagger$ & $p<0.01 \ddagger$ & $p<0.01$ \\
\hline Insomnia & $p<0.01 \$$ & NS & NS \\
\hline Appetite loss & $p<0.01 \dagger$ & NS & $p<0.01$ \\
\hline Nausea and vomiting & $p<0.01 \ddagger$ & NS & $p<0.01 \S$ \\
\hline Constipation & $p<0.01 \dagger$ & $p<0.05 \dagger$ & NS \\
\hline Diarrhoea & NS & NS & $p<0.01$ \\
\hline Cognitive function & $p<0.01 \ddagger$ & $p<0.05 \ddagger$ & $p<0.01$ \\
\hline Emotional role & $p<0.01 \ddagger$ & $p<0.01 \ddagger$ & $p<0.05$ \\
\hline Social role & $p<0.01 \dagger$ & NS & $p<0.05$ \\
\hline Financial difficulties & NS & NS & NS \\
\hline Global health status & $p<0.01 \dagger$ & $p<0.01 \dagger$ & $p<0.01$ \\
\hline Symptom experience & $p<0.01 \%$ & $p<0.05 t$ & $p<0.01$ \\
\hline Lymphoedema & NS & NS & NS \\
\hline Peripheral neuropathy & NS & $p<0.01 \uparrow$ & $p<0.01$ \\
\hline Menopausal symptoms & NS & NS & NS \\
\hline Body image & $p<0.01 \dagger$ & $p<0.01 \dagger$ & $p<0.05$ \\
\hline Sexual worry & $p<0.01 \%$ & NS & NS \\
\hline Sexual activity & $p<0.01 \dagger$ & NS & NS \\
\hline Sexual/vaginal functioning & NS & NS & $p<0.01$ \\
\hline Sexual enjoyment & $p<0.05 \dagger$ & NS & $p<0.01$ \\
\hline
\end{tabular}

NS, not significant.

$\dagger$, Improved; $\$$, decreased; $\S$, HIV $+>$ HIV-

All other $p$ values in column HIV- > HIV

role function, insomnia, constipation, sexual worry and sexual activity (Table 2). Global health improved in both groups, with HIV-negative women experiencing a greater improvement. PN did not change in HIV-negative women but HIV-positive women experienced an initial decline in this symptom at post treatment with a return to pretreatment values at the 3-month follow-up visit. The change in PN was statistically significantly different between HIV-negative and HIV-positive women.

\section{Discussion}

The results of the study show significant demographic differences between HIV-positive and HIV-negative women with a diagnosis of cervical cancer. The former group is statistically younger, and has a higher educational level and higher unemployment rate than the latter. Black women have a statistically higher HIV-positivity rate than mixed race and white women. Single women had the highest HIV-positivity rate. Monthly income is similar in both groups. RT was more frequently used than CR in HIVpositive patients. The $22 \%$ HIV-positive rate in the current study is higher than previously reported rates. This change is the result of a general change in HIV-positive rates in the total population over time. ${ }^{2}$ Black women had a higher HIVpositive rate than mixed race or white women. A previous study documented a higher incidence $(30 \%)$ of positive syphilis serology amongst black women with cervical cancer than in their white and mixed race counterparts. ${ }^{12}$ The younger age of HIV-positive cervical cancer patients confirms previous studies of HIV in cervical cancer cases. In previous studies, the difference in mean age between 
HIV-negative and HIV-positive patients was reported as 10 years, whilst the current study shows a 7-year age difference. ${ }^{5,13,14}$ The stage distribution in the current study was similar in HIV-negative and HIV-positive women. Despite the similar stage distribution, significantly more HIV-negative than HIV-positive women received CR. The selection by the presiding clinician of the inability of HIVpositive women to tolerate the chemotherapy because of low CD4 counts, gave rise to this difference.

The majority of QOL domains in HIV-negative women improved with treatment with prolonged effect up to 3 months' follow-up. Improvement of QOL domains in HIVpositive women was statistically less than in HIV-negative women. PN domain did not change in HIV-negative women. In HIV-positive women, initial improvement occurred in PN with relapse to pretreatment level at 3 months. Appetite loss in HIV-positive women initially improved after treatment and returned to pretreatment levels at 3 months' follow-up. HIV-negative women showed an improvement in appetite loss up to 3 months' follow-up. The QOL of HIV-negative women significantly improved in the majority of domains. HIV-positive women had fewer domains improved by treatment, and the magnitude of improvement was less than that amongst HIV-negative women. Temporary improvement of pain, fatigue and appetite loss after treatment in HIV-positive women reverted to pretreatment levels at 3 months' follow-up. Pain and fatigue are AIDSrelated conditions that are prevalent in AIDS patients, despite adequate treatment. Depression is associated with these symptoms, and the difference in emotional functioning in the current study underlines the element of depression in the HIV-positive women. ${ }^{15}$ The AIDS-related impact on QOL accounts for these relapses in QOL domains. Diarrhoea was significantly more in HIV-positive women than in HIVnegative women, and treatment did not change the incidence in either group. Diarrhoea is commonly associated with AIDS and can have numerous causes, both infectious and non-infectious, for example AIDS medication-related gastrointestinal side-effects. ${ }^{16}$ Constipation improved in both HIVnegative and HIV-positive women. Radiation is associated with increased stool frequency owing to radiation-induced mucosal rectal damage. PN paradoxically improved in both groups after treatment and reverted to pretreatment levels in HIV-positive women. Contrary to expected cisplatinrelated toxicity, treatment did not result in an increase of PN. The dose of cisplatin, which did not reach the cumulative threshold dose $>250 \mathrm{mg}-350 \mathrm{mg} / \mathrm{m}^{2}$, may explain the absence of PN. Cisplatin-associated PN may occur up to 8 months after exposure, and therefore longer follow-up may reveal PN. ${ }^{17}$

In the present study, higher rates of loss to follow-up occurred in HIV-positive women. A meta-analysis of subSaharan low- and middle-income countries' antiretroviral treatment programmes reports on causes of loss to follow-up. Self-transferring care to other facilities (18.6\%), unreported death $(38.8 \%)$ and stopping treatment were identified as the major reasons for loss to follow-up. ${ }^{18}$
WHO AIDS stage 3 and 4 cases have a mortality rate of 72.12 per 100 person-years in the first 6 months after initiation of treatment. The mortality rate decreases to 7.9 per 100 person-years after 12 months. ${ }^{19}$ The mortality rate is compounded by cervical cancer-related death. In a South African study, the mortality rate after treatment of stage III cervical cancer was the highest in the first 6 months after treatment. ${ }^{12}$ In Kenya, a $41 \%$ loss to follow-up occurred in women receiving treatment for cervical cancer. ${ }^{20}$ Tracking of women after missed appointments is not done routinely owing to resource constraints. ${ }^{18}$ Verifying HIV-related deaths by checking death certificates is subject to $90 \%$ misclassification of HIV deaths in South Africa. ${ }^{21}$

Limitations of the present study include a short follow-up subsequent to completion of therapy. The short followup limits the conclusion to long-term effects of treatment. Prolonged follow-up may reveal an increased incidence of PN. The higher loss to follow-up rate of HIV-positive women during the study period precludes sub-analysis of smaller groups, for example treatment-related $\mathrm{PN}$ in those women undergoing CR.

In conclusion, the study documents the demographic difference in HIV-negative and HIV-positive women with cervical cancer with regard to a younger age in the latter group. The 5-year survival benefit of $\mathrm{CR}$ in comparison with RT in HIV-negative women with stage III to IVA is a statistically non-significant 3\%. ${ }^{6}$ The poor response of HIVpositive women to $C R$ raises the question of whether $C R$ is appropriate in these circumstances. ${ }^{5}$ A significant difference exists in the short term in certain QOL domains of HIVpositive women with cervical cancer receiving RT or CR. In these circumstances, the different impact on long-term QOL of HIV-positive women with cervical cancer receiving RT or CR warrants further study.

\section{Acknowledgements}

The research forms part of a PhD thesis (GCDT) with promotor Prof. T.F. Kruger, Department of Obstetrics and Gynaecology, Stellenbosch University. The members of the Unit of Gynaecological Oncology, Tygerberg Hospital and the head of the unit, Prof. M.H. Botha, are acknowledged for their assistance.

\section{Competing interests}

The authors declare that they have no financial or personal relationships which may have inappropriately influenced them in writing this article.

\section{Authors' contributions}

G.d.T. (Stellenbosch University) was the project leader and designed the study, wrote the protocol, collected the data and wrote the paper. M.K. (Stellenbosch University) performed the statistical analysis and contributed to discussions. Both authors read and approved the manuscript. 


\section{References}

1. Black J, Conradie F, Cox V, et al. Adult antiretroviral therapy guidelines 2014 by the Southern African HIV Clinicians Society. S Afr J HIV Med. 2014;15:121-143.

2. Shisana O, Rehle T, Simbayi LC, et al. South African national HIV prevalence, incidence and behaviour survey, 2012. Cape Town: HSRC Press; 2014.

3. Arbyn $M$, Castellsague $X$, de Sanjose $S$, et al. Worldwide burden of cervical cancer in 2008. Ann Oncol. 2011;22:2675-2686. PMID: 21471563, http://dx.doi. org/10.1093/annonc/mdr015

4. Wadley AL, Cherry CL, Price P, Kamerman PR. HIV neuropathy risk factors and symptom characterization in stavudine-exposed South Africans. Pain Symptom Manage. 2011;41:700-706. http://dx.doi.org/10.1016/j. jpainsymman.2010.07.006

5. Simonds HM, Wright JD, du Toit N, Neugut Al, Jacobson JS. Completion of and early response to chemoradiation among human immunodeficiency virus (HIV)positive and HIV-negative patients with locally advanced cervical carcinoma in South Africa. Cancer. 2012;118:2971-2979. PMID: 22072021, http://dx.doi. org/10.1002/cncr.26639

6. Chemoradiotherapy for Cervical Cancer Meta-analysis Collaboration (CCCMAC) Reducing uncertainties about the effects of chemoradiotherapy for cervical cancer: Individual patient data meta-analysis. Cochrane Database Syst Rev. 2010;Issue 1. Art. No.: CD008285. PMID: 20091664, http://dx.doi.org/10.1002/14651858. CD008285

7. Western Cape Provincial Treasury. Regional development profile City of Cape Town. 2012 [cited 2014 Jul 23]. Available from: http://www.westerncape.gov.za/ assets/departments/treasury/dc0_city_of_cape_town_sep-lg_profile_02_2013. pdf

8. Pecorelli S. Revised FIGO staging for carcinoma of the vulva, cervix, and endometrium. Int J Gynaecol Obstet. 2009;105:103-104. PMID: 19367689, http:// dx.doi.org/10.1016/j.ijgo.2009.02.012

9. Du Toit GC, Nel D. Translation and validation of European Organisation for Research and Treatment of Cancer QLQ-CX24 questionnaire into the indigenous African languages of isiXhosa and Afrikaans. S Afr J Gynecol Oncol. 2012;4:59-62.

10. Aaronson NK, Ahmedzai S, Bergman B, et al. The European Organization for Research and Treatment of Cancer QLQ-C30: A quality-of-life instrument for use in international clinical trials in oncology. J Natl Cancer Inst. 1993;85:365-376. PMID: 8433390.
11. Greimel ER, Kuljanic Vlasic K, Waldenstrom AC, et al. The European Organization for Research and Treatment of Cancer (EORTC) Quality-of-Life questionnaire cervical cancer module: EORTC QLQ-CX24. Cancer. 2006;107:1812-1822. PMID: 16977652.

12. Du Toit GC, Smit BJ. Clinical prognostic parameters in stage III cervical carcinoma: An analysis of 732 patients. S Afr Med J. 1997;87:1434-1440.

13. Lomalisa $P$, Smith $T$, Guidozzi $F$. Human immunodeficiency virus infection and invasive cervical cancer in South Africa. Gynecol Oncol. 2000;77:460-463. PMID: 10831360, http://dx.doi.org/10.1006/gyno.2000.5775

14. Moodley M, Mould S. Invasive cervical cancer and human immunodeficiency virus (HIV) infection in KwaZulu-Natal, South Africa. J Obstet Gynaecol. 2005;25:706-710. PMID: 16263548, http://dx.doi.org/10.1080/01443610500294599

15. Matilda B, Streinu-Cercel A, Mariana M, et al. Fatigue in Hiv/Aids patients. Ther Pharmacol Clin Toxicol. 2012;16:111-115.

16. Feasey NA, Healey P, Gordon MA. Review article: The aetiology, investigation and management of diarrhoea in the HIV-positive patient. Aliment Pharmaco Ther. 2011;34:587-603. PMID: 21777262, http://dx.doi.org/10.1111/j.13652036.2011.04781.x

17. Grisold W, Cavaletti G, Windebank AJ. Peripheral neuropathies from chemotherapeutics and targeted agents: Diagnosis, treatment, and prevention. Neuro Oncol. 2012;14(Suppl 4):iv45-54. PMID: 23095830, http://dx.doi org/10.1093/neuonc/nos203

18. Wilkinson LS, Skordis-Worrall J, Ajose O, Ford N. Self-transfer and mortality amongst adults lost to follow-up in ART programmes in low- and middleincome countries: Systematic review and meta-analysis. Trop Med Int Health 2015;20:365-379. PMID: 25418366, http://dx.doi.org/10.1111/tmi.12434

19. Wubshet M, Berhane Y, Worku A, Kebede Y. Death and seeking alternative therapy largely accounted for lost to follow-up of patients on ART in northwest Ethiopia: A community tracking survey. PLoS One. 2013;8:e59197. PMID: 23527132, http:// dx.doi.org/10.1371/journal.pone.0059197

20. Maranga IO, Hampson L, Oliver AW, et al. Analysis of factors contributing to the low survival of cervical cancer patients undergoing radiotherapy in Kenya. PLoS One. 2013;8:e78411. PMID: 24205226, http://dx.doi.org/10.1371/journal. pone.0078411

21. Birnbaum JK, Murray CJL, Lozanoa R. Exposing misclassified HIV/AIDS deaths in South Africa. Bull World Health Organ. 2011;89:278-285. PMID: 21479092 http://dx.doi.org/10.2471/BLT.11.086280 